\title{
La percepción de los judíos bajo el reinado de Fernando II según el inquisidor don Martín García (ca. 1441-1521**
}

Perception of the Jews during the reign of Ferdinand II
according to the Inquisitor Don Martín García

(ca. 1441-1521)

\author{
Manuel MONTOZA COCA \\ Universitat Autònoma de Barcelona \\ Departament de Ciències de l'Antiguitat i de l'Edat Mitjana \\ Facultad de Filosofía y Letras \\ manuel.montoza@uab.cat
}

\begin{abstract}
Many political and religious changes took place in the Kingdom of Aragon during the government of King Ferdinand the Catholic. Of these, changes in the relationship with the Jewish community are specially relevant. The most significant moment of the period was, without any doubt, the order of expulsion of the Jews from all Hispanic kingdoms, issued in 1492. In this paper we present and analyze the perception of the Jews during this period, using as a reference passages from the Sermones by the Inquisitor Don Martín García, Bishop of Barcelona and King Ferdinand II's royal preacher, as a source.
\end{abstract}

Keywords: Jews, Sermones, Martín García, 15th century, Crown of Aragon.
Resumen: Durante el gobierno del rey Fernando el Católico, en la Corona de Aragón se produjeron multitud de cambios de carácter tanto político como religioso, en especial en relación con la comunidad judía. El momento más significativo es, sin duda, el decreto de expulsión de los judíos de los reinos hispanos en 1492. En este trabajo se pretende exponer y analizar la imagen que se tiene de los judíos en este período, tomando como fuente algunos pasajes de los Sermones del inquisidor Don Martín García, obispo de Barcelona y predicador real del rey Fernando II.

Palabras clave: judíos, Sermones, Martín García, siglo XV, Corona de Aragón.

* Este trabajo se ha elaborado gracias a la beca FI-DGR (Ref. 2015FI_B 00055) en el marco de los proyectos de investigación «Fuentes medievales y modernas para el estudio de las relaciones transculturales en el Mediterraneo: redacción y transmisión» FFI2015-63659-C2-1-P (MINECOFEDER 2016-2018), y «La percepció de l'Islam en la societat cristiana. Les traduccions llatines de l'Alcorà i la Literatura Llatina medieval de controversia amb l'Islam i el Judaisme», 2014 SGR 53 de la AGAUR de la Generalitat de Catalunya. 


\section{INTRODUCCIÓN}

Durante las últimas décadas del siglo XV y las iniciales del siglo XVI Don Martín García ocupó un lugar de suma relevancia en el ámbito de la Corona de Aragón. Nacido en Caspe, en el seno de una familia humilde de cristianos viejos, ingresó como «seise» o «infantillo» en la Seo de Zaragoza ${ }^{1}$. Allí, al parecer, demostró ser un estudiante muy despierto y capaz, por lo que en 1476 fue enviado a Bolonia a completar su formación como teólogo ${ }^{2}$. Ya con el título de Maestre en Teología ${ }^{3}$, tras regresar del Colegio de Españoles de San Clemente de Bolonia en 1480, en 1481 ingresó como Canónigo en la Seo de Zaragoza ${ }^{5}$. Posteriormente, hacia 1484 , fue nombrado inquisidor ordinario, tal y como se refleja en una carta enviada por el rey Fernando II, en la que consta el pago a Martín García de mil sueldos:

Don Ferrando, etc., (...) dezimos y mandamos con la presente que (...) deys y paguéis en cada un anyo a los Inquisidores y ministros de la dicha Inquisición de yuso escritos las quantías siguientes: (...) a maestre Martín García, canónigo e ordinario, mil sueldos ${ }^{6}$.

A partir del año 1487, Martín García se convierte en predicador real de Fernando II y en confesor personal de la reina Isabel de Castilla, tras predicar ante ambos un sermón durante una estancia de los monarcas en Zaragoza ${ }^{7}$. Finalmente, ocupará también los cargos de obispo electo de Messina (cuyo ejercicio declinó), arcediano de Daroca y, por último, obispo de Barcelona, dignidad que desempeñó hasta 1519. En esta fecha, dada su avanzada edad, decidió retirarse a su villa natal de Caspe, donde murió el 7 de marzo de 1521, a los ochenta años ${ }^{8}$.

1 José De Hebrera, Vida prodigiosa del ilustrísimo y venerable Don Martín García, obispo de Barcelona, bijo de la fidelissima y antigua villa de Caspe, Zaragoza, 1700, p. 33.

2 Ibid. [ver n. 1], pp. 36-37.

3 Acerca del título de Maestre en Teología, vid. Antonio PÉREZ MarTín, Proles Aegidiana, 1. Introducción. Los colegiales desde 1368 a 1500 (Studia Albornotiana, 31), Bolonia, 1979, p. 384.

4 José DE Hebrera, Vida ... [ver n. 1], p. 57.

5 Ibid. [ver n. 2], p. 59.

6 Barcelona, ArXiu de la Corona D'Aragó, Cancilleria, reg. 3684, ff., $16 \mathrm{r}^{\circ}-16 \mathrm{v}^{\circ}$. Vid. Juan Francisco SÁNCHEZ LóPez, Martín García Puyazuelo. La ética de Catón (Textos aragoneses, 62), Zaragoza, 2009, p. 17. Vid. José Ángel SESMA MUÑOZ, El establecimiento de la Inquisición en Aragón (1484-1486) (Fuentes históricas aragonesas, 15), Zaragoza, 1987, p. 43.

7 José DE Hebrera, Vida... [ver n. 1], pp. 102-103. Vid. etiam: Juan Francisco ANDrÉs DE UzTÁRROZ, Progressos de la Historia en el Reyno de Aragon, y elogios de Geronimo Zurita, su primer coronista (...), Zaragoza, 1680, p. 266.

8 Juan Francisco SÁNCHEZ López, Martín García... [ver n. 6], p. 12. 


\section{Muerte DE PEDRO DE ARBUÉS (1441-1485)}

En el año 1485 se produjo un suceso que influyó sobremanera en el carácter y la actitud de la sociedad zaragozana hacia los conversos y que favoreció el arraigo de la Inquisición en la ciudad ${ }^{9}$. La noche del 14 al 15 de septiembre, el amigo y protector de Martín García, Pedro de Arbués, es acuchillado ante el altar mayor de la propia Seo, presuntamente, por un grupo de judeoconversos ${ }^{10}$. Durante el subsiguiente proceso judicial, que se alargó tres años, hasta 1488, se realizaron catorce autos de fe en 1486, diez en 1487 y finalmente siete en $1488^{11}$.

Parece ser que Martín García formó parte del tribunal que se encargó de juzgar a los sospechosos del asesinato de su amigo y protector, y es del todo plausible que se le permitiera seguir el proceso a petición propia, en calidad de vicario y canónigo de Zaragoza. Por otra parte, la actividad de Don Martín como predicador está atestiguada en, al menos, siete autos ordinarios de inquisición celebrados en Zaragoza entre 1486 y $1488^{12}$. De hecho, hay menciones a Don Martín como juez de los acusados por el asesinato de Arbués:

Consta que Alonso Sanchez de Alarcon, y Fray Miguel de Monterrubio, inquisidores de Zaragoza, juntos con Martin García, vicario general del arzobispo, condenaron en 20 de Junio de 86 á Juan de Esperaindeo, y en 25 de Enero de 87 á Juan de la Abadía, á ser relaxados á la justicia seglar para morir quemados como hereges judaizantes, impenitentes y reos de la muerte del inquisidor Arbués ${ }^{13}$.

Asimismo, durante dicho proceso judicial, en el año 1487, Martín García fue nombrado inquisidor apostólico de Barcelona: «(...) Torquemada nombró á 3 de Abril de dicho año de 87 por inquisidor de Barcelona á Martin Garcia, canonigo de

9 Daniel Rico CAMPs, La imagen de Pedro Arbués. Literatura renacentista y arte medieval en torno a don Alonso de Aragón, en Locus Amoenus, 1 (1995), pp. 107-119, p. 108: «no hará falta insistir en la importancia que tuvieron para la consolidación y definitivo arraigo del Tribunal del Santo Oficio en Aragón tanto el asesinato del inquisidor Pedro de Arbués a manos de ricos conversos, en septiembre de 1485, como el culto que se le rindió post mortem». Vid.etiam: Irene GONZÁLEZ HERnÁNDO y Diana OlIVARES MARTíNEZ, Los reyes católicos y los lugares de memoria de los santos dominicos, en José Ángel GARCÍA DE CORTAZAR y Ramón TEJA (eds.), Los monasterios medievales en sus emplazamientos: lugares de memoria de lo sagrado, Aguilar de Campoo, 2016, pp. 249-281, p. 270: «De hecho, el culto post mortem a Pedro de Arbués, rendido en torno a su sepulcro, facilitó la aceptación de la Inquisición en Aragón».

10 Henry Kamen, La inquisición española, Barcelona, 2013, p. 89.

11 José MartíneZ Millán, La inquisición española, Madrid, 2007, p. 83.

12 Henry Charles LEA, Historia de la Inquisición española, t. 1, Madrid, 1983, pp. 856-876.

13 Juan Antonio LLORENTE, Memoria histórica sobre qual ha sido la opinion nacional de España acerca del Tribunal de la Inquisición, Madrid, 1812, p. 109. 
Zaragoz $a^{14} \gg$. Por otra parte, Don Martín en ocasiones es llamado «inquisidor de la Santa $F e^{15} \gg 0$ «inquisidor contra la herética pravedad ${ }^{16} »$, y siempre se pone de manifiesto su estrecha relación con su antecesor, Pedro de Arbués, del que «fue sucessor del Santo Oficio de Inquisidor ${ }^{17}{ }^{7}$.

En $1520^{18}$, un año antes de morir, el canónigo de Zaragoza, Agustín Oliván, publicó, con el beneplácito y la supervisión de Martín García, una selección de $156^{19}$ de los sermones del Maestre, predicados aproximadamente entre 1490 y $1510^{20}$. En estos sermones, impresos íntegramente en latín ${ }^{21}$, Don Martín García hace mención hasta en tres ocasiones a su mentor Pedro de Arbués:

En nuestros tiempos fue martirizado el maestro Épila en la iglesia de Zaragoza por su fe a Cristo, mientras era inquisidor de la herética pravedad ${ }^{22}$.

Como hemos visto anteriormente, la relación entre ambos inquisidores debió de ser estrecha y Martín García no pierde la ocasión de recordar en sus sermones a su amigo, acusando de su asesinato a los herejes:

(La reina Isabel) envío la séptima (saeta) contra los herejes, pues era muy celante de la fe católica. Así pues, favorecía a todos los inquisidores, en medida tal que, cuando en Zaragoza, por su fe a Cristo, fue asesinado por los herejes el beato Pedro Arbués, inquisidor de esta ciudad, y como viese (la reina) que no estaba sepultado en un lugar decente, de su propio bolsillo y sin reparar en gastos, ordenó construir para él una sepultura en medio de esta iglesia ${ }^{23}$.

14 Juan Antonio LloRente, Memoria... [ver n. 13], p. 118.

15 Juan Agustín CARRERAS RAMÍREZ y ORTA, Discursos panegiricos de santos, golfo de la passion de fesus y el proceloso mar de los dolores de Maria, Zaragoza, 1730, p. 403.

16 José DE HEBRERA, Vida... [ver n. 1], p. 163.

17 Juan Agustín CarReras RaMíreZ y ORTA, Discursos... [ver n. 15], p. 403.

18 José DE Hebrera, Vida... [ver n. 1], p. 76.

19 Manuel Montoza Coca, Hacia una edición crítica de los Sermones de Don Martín García, en Medievalia (en prensa).

20 Manuel Montoza Coca, La exégesis bíblica en la polémica contra judíos: los Sermones de Don Martín García (ca. 1441-1521), en Mélanges de la Casa de Velázquez (en prensa).

21 Sebastián CiRAC EstopaÑáN, Los sermones de don Martín García obispo de Barcelona sobre los Reyes católicos, Barcelona, 1955 , p. 6.

22 Martín GARCÍA, Sermones eminentissimi totiusque Barchinonensis gregis tutatoris acerrimi, necnon inmarcessibilis sacre theologie paludamento insigniti Martini Garsie, Zaragoza, 1520, f. 297vo: temporibus nostris magister Epila martyrizatus pro fide Christi, dum esset inquisitor beretice pranitatis in ecclesia Cesaraguste.

23 Martín GARCÍA, Sermones... [ver n. 22], f. 476r': Septima misit contra hereticos, nam erat multum zelatrix fidei catholice. Fauebat enim omnibus inquisitoribus, in tantum quod cum Ceseraguste per hereticos interfectus fuisset pro fide Christi beatus Petrus Arbues istius ciuitatis inquisitor et uidetur quod non in decenti loco esset sepultus, magnis et propriis expensis illi sepulturam fieri fecit in medio ecclesie buius. 
La tercera ocasión en la que el obispo de Barcelona se refiere a Pedro de Arbués, lo hace estableciendo una comparativa con el mártir Pedro de Verona, dominico del siglo XIII, asesinado el 6 de abril de 1252 en circunstancias similares al inquisidor Zaragozano. La muerte de este último es rápidamente interpretada por Martín García como un martirio y usada con el fin de convertir a los judíos reticentes:

No sólo mientras viven (los santos), sino también tras la muerte hacen milagros, como se demuestra con el beato inquisidor de esta iglesia, por cuya intercesión Dios ha hecho muchos milagros en estos tiempos. Pues éste fue muerto para iluminar la fe católica, de modo que, tal y como hay dos apóstoles en la iglesia de Dios, a saber: Pedro en oriente y Jacobo en occidente, y tal y como dos confesores trajeron luz a la iglesia, a saber: Francisco en oriente y Domingo en occidente, de este modo hubo dos mártires e inquisidores; uno en oriente, como es san Pedro Veronense, otro en occidente, a saber: Pedro Zaragozano, quien fue muerto por la fe a Cristo. Y así, san Pedro Mártir fue muerto por los herejes, así éste por los herejes asesinado ${ }^{24}$.

\section{LA RELACIÓN ENTRE MARTÍN GARCÍA Y FERNANDO II}

En el marco de la política unificadora de los reyes católicos, la postura de la Inquisición en relación a la monarquía era de proximidad. En los primeros años, tras su implantación en la Corona de Aragón en 1483, la Inquisición (y los inquisidores a título personal) mantuvo una actitud cauta y prudente, limitándose a actuar en casos muy puntuales, sobre todo hasta la muerte de Arbués ${ }^{25}$.

A partir de este momento, la cercanía entre el aparato inquisitorial y el monarca entra en un estado de mayor colaboracionismo ${ }^{26}$, en perjuicio de las comunidades

24 Martín GaRCÍA, Sermones... [ver n. 23], f. 109ro: non solum uiuentes, sed etiam post mortem faciunt miracula, ut patet de inquisitore beato buius ecclesie, per intercessionem cuius isto tempore multa facit mirabilia Deus. Hic autem mortuus fuit pro illuminatione fidei catholice, ut sicut duo apostoli in ecclesia Dei, scilicet: Petrus in oriente et Iacobus in occidente, et duo confessores illuminauerunt ecclesiam, scilicet: Franciscus in oriente et Dominicus in occidente, sic duo martyres et inquisitores; unus in oriente ut sanctus Petrus Veronensis, alius esset in occidente, scilicet: Petrus Cesaragustanus, qui mortuus fuit pro fide Christi. Et sic sanctus Petrus Martyr ab hereticis mortuus fuit, sic iste ab bereticis interfectus.

25 Jaime CONTRERas, Fernando el Católico y la Inquisición en Aragón, en Fernando II de Aragón, el rey católico, Zaragoza, 1996, p. 350.

26 Ángel AlCalá, Los judeoconversos en la cultura y sociedad españolas, Madrid, 2011, p. 198: «Desde ese momento (la muerte de Arbués) ya era el Rey dueño de la situación y quedaba abierta la vía por la que él y sus sucesores, al alimón con inquisidores aragoneses y castellanos, podían continuar su tarea $(. ..) \gg$. 
judías y musulmanas. Tras el decreto de expulsión de los judíos del 31 de marzo 1492 y la pragmática de conversión forzosa del 14 de febrero 1502 contra los musulmanes, sobre el papel no quedaba ningún judío o musulmán dentro de las fronteras peninsulares, sino que únicamente permanecían aquellos que se habían convertido: los judeoconversos y los moriscos ${ }^{27}$. En cierta medida, la intención real de los decretos (sobre todo del de 1492) era la de provocar el aumento del número de conversiones y acabar con las prácticas religiosas disidentes a la ortodoxia cristiana ${ }^{28}$.

En este contexto, la preocupación de Don Martín García se centra, por un lado, en intentar realizar el mayor número de conversiones posible, de aquellos que, supuestamente, no han abrazado la fe católica de forma sincera. Por otra parte, el Maestre tiene especial interés en desterrar las malas costumbres instaladas entre la población cristiana ${ }^{29}$. Es el suyo un discurso destinado a reforzar la fe y afianzar las creencias de los malos cristianos viejos y de los conversos, impartiendo, mediante sus sermones, enseñanzas basadas en el arrepentimiento, la confesión de la herejía ${ }^{30}$ y el bautismo ${ }^{31}$.

Es relativamente frecuente que el predicador aluda o haga referencia al rey Fernando, que sabemos que pudo estar presente en algunos de sus sermones ya que le interpela directamente, como por ejemplo en el sermón número 154 de la compilación:

Serenísimo príncipe, las palabras tomadas como tema y que han de ser declaradas ante vuestra majestad, son las palabras del rey David en los Salmos y vertidas del latín en nuestra lengua vulgar, que quieren decir, según mi parecer, que la justicia y la paz en estos días pasados estuvieron en una inmensa tristeza. Mas ahora, a causa de la nueva llegada de vuestra majestad, hicieron y tuvieron el mayor de los gozos y se besaron. Y como veo que vuestra majestad está algo fatigada a causa del esfuerzo del viaje, en el presente sermón sólo pronunciaré una conclusión ${ }^{32}$.

27 Acerca del proceso de conversión en profundidad, vid. James S. AmELANG, Historias paralelas: Fudeoconversos y moriscos en la España moderna, Madrid, 2011, passim.

28 Henry Kamen, La expulsión: finalidad y consecuencias, en Elie KedOURIE (ed.), Los judíos de España, Barcelona, 1992, p. 95.

29 Martín GARCÍA, Sermones... [ver n. 22], f. 466v : iam quis peccat cum filia sua, cum sorore, cum consanguinea, etcetera. Item iam uendunt mulieres in publico et non possunt a peccato separari. Iam mulieres sunt bomines et homines mulieres, quia mulieres decaluantur et homines portant mulierum capillos. Solebant autem mulieres mamillas ostendere, nunc uiri ostendunt pectora et sic portant habitum mulierum.

$30 \mathrm{Ibid}$., f. $148 \mathrm{v}^{\circ}$ : peccator ante confessionem uidetur quod babeat maximum pondus supra se, sed facta confessione uidetur esse liberatus.

31 Ibid., f. $213 \mathrm{v}^{\circ}$ : [peccator], si habet peccatum infidelitatis et heresis, debet caput lauare per baptismum in infideli et per abiurationem in beretico.

32 Ibid., ff. 472rv': serenissime princeps, uerba thematis assumpta et coram maiestate uestra declaranda sunt uerba regis Dauid in Psalmis et uersa de latino in lingua uulgari nostra ad propositum meum sonant 
Estas alocuciones dirigidas directamente al rey, como decimos, son habituales en la obra del Maestre. En algunos casos, al margen de las preceptivas fórmulas protocolarias y de respeto, Don Martín se permite aconsejar al rey e incluso, en algunos casos, reclamarle algunas acciones:

Y así esperamos, ilustrísimo príncipe, que, mediante vuestra justicia, Zaragoza, ciudad que ahora permanece disipada por la discordia de los ciudadanos, la cual no gobierna sobre nada, llegue a devenir [ciudad] de Dios. Tal y como dispersasteis a los herejes y judíos, así también reduzcáis a la fe de Cristo a los agarenos que en ella viven ${ }^{33}$.

\section{O reprocharle otras:}

La tercera plaga fue la de los mosquitos hechos del polvo; éstos son los hombres aduladores. En esta ciudad nadie hay que se atreva a decir la verdad ante los príncipes, prelados y mayores, sino que todos les elogian sus vicios y pecados ${ }^{34}$.

Esta relativa franqueza con la que el predicador dominico se expresa se puede explicar por dos razones: en primer lugar, como hemos apuntado, Don Martín García se destacó en la conversión de judíos y en su persecución, en especial desde la muerte de Pedro de Arbués. Esta secuencia de acontecimientos propicia que el predicador ascienda rápidamente en el escalafón eclesiástico, convirtiéndose en inquisidor apostólico, una figura jerárquica respetada y temida por la población. Por otra parte, se trata de un momento en que la relación de la iglesia con la monarquía es estrecha y la necesidad de colaborar es mutua ${ }^{35}$. La necesidad de Fernando II de mantener buenas relaciones con la Inquisición, junto con la necesidad de la Inquisición de contar con la protección

quod iustitia et pax his diebus elapsis erunt in maxima tristitia. Sed nunc propter aduentum nouum uestre maiestatis fecerunt et habuerunt maximum gaudium, et sic osculate sunt. Et quia uideo quod maiestas uestra propter laborem itineris est aliqualiter fatigata, ideo in presenti sermone solam unam declarabo conclusionem.

33 Martín GARCía, Sermones... [ver n. 22], f. 298r ${ }^{\circ}$ : et sic speramus, illustrissime princeps, quod mediante iustitia uestra Cesaragusta fiet ciuitas que nunc manet dissipata discordia ciuium que nulla regnat et fiet Dei. Sicut dissipastis hereticos et iudeos, sic etiam reducetis ad fidem Christi agarenos in illa existentes.

$34 \mathrm{Ibid}$, f. $467 \mathrm{r}^{\circ}$ : tertia plaga fuit scinifes facti ex puluere, qui sunt homines adulatores. In hac ciuitate nullus est qui apud principes, prelatos et maiores audeat ueritatem dicere, sed omnes laudant eos de uitiis et peccatis.

35 Pilar Huerga CRIAdo, El inquisidor general fray Tomás de Torquemada. Una inquisición nueva, en Inquisición española, nuevas aproximaciones, Madrid, 1987, p. 17. 
del rey provoca que, en ocasiones, Don Martín se permita criticar, si bien no abiertamente, algunas de las situaciones por las que pasa el país: «sobre todo bay en España esta corruptela, pues a causa de esta pompa se empobrece ${ }^{36} \gg$.

\section{EL TÓPICO DEL JUDÍO COMO EJEMPLO DE LA CEGUERA}

Uno de los «topoi» o lugares comunes más extendidos en la literatura de controversia y de polémica religiosa cristiana es la ceguera de los judíos ${ }^{37}$. Este es un recurso literario muy extendido y fundamental de la controversia clásica desde la patrística, usado por autores como Pedro Alfonso de Huesca o Alfonso de Espina en su Fortalitium Fidei, en cuyas ilustraciones incluso se pueden ver representados a los judíos con vendas cubriéndoles los ojos ${ }^{38}$. El hecho de que los judíos no reconozcan a Jesús como el verdadero mesías tiene también una larga tradición y aparece en obras como el Pugio Fidei de Ramón Martíi o los Errores y falsedades del Talmud de Jerónimo de Santa Fe ${ }^{40}$. Martín García considera que los judíos no es que actúen por maldad innata, sino porque su ceguera les impide ver lo que es evidente, a saber, que la llegada del mesías ya se ha producido y que es Jesús de Nazaret:

Así fueron el pueblo judío y gentil; el judío estaba acostumbrado a continuar con alguna luz de la antigua ley, y una vez llegó Cristo, cesó la luz de la ley y por ello

36 Martín GARCía, Sermones... [ver n. 22], f. 305v $\mathrm{v}^{\mathrm{0}}$ : Maxime est in Hispania hec corruptela, nam propter banc pompam depauperantur.

37 Jordi CASANOVAS MIRÓ, Aspectos cotidianos en la relación entre judios y cristianos. La imagen que del judío tiene el cristiano, en Yolanda MORENO KOCH, Ricardo IZQUIERDO BENITO (coords.), Del pasado judío en los reinos medievales hispánicos, Cuenca, 2005, p. 121: «se desarrolla una abundante literatura antijudía en lengua vulgar cuyo objetivo es poner de manifiesto la ceguera y la cerrazón judáica».

38 Vid. Paulino Rodríguez BARRAL, Contra caecitatem iudeorum: el tópico de la ceguera de los judíos en la plástica medieval hispánica, en Ilu. Revista de Ciencias de las Religiones, 12 (2007), pp. 181-209, p. 201.

39 Jeremy CoHen, The Friars and the fews, the evolution of medieval anti-judaism, Londres, 1982, pp. 132-133: Part two (of Pugio Fidei) seeks to prove that the messiab has already come. Martini devotes considerable attention to several outs anding messianic prophecies of the Old Testament [...] arguing that they already had to have been fulfilled and that they, as well as all other such biblical allusions to the messiah, can refer to no one else but Fesus. Even the Talmud could be shown to acknowledge the advent of the messiah.

40 Jerónimo DE SANTA FE, Errores y falsedades del Talmud, ed. por Carlos Del VALle, Madrid, 2006, p. 92: «E ya sea que en el mes de Agosto más çirca passado por mandamiento del dicho bienaventurado Padre yo oviese conplido un breve Tractado en el qual traxe muchas abtoridades del dicho Talmud por afirmar ser nuestro Salvador Ihesu Christo masías verdadero prometido por todos los prophetas (...)». 
devino ciego. Pero el pueblo gentil, acostumbrado a andar en tinieblas, aceptó la luz cuando llegó el sol del mesías, porque antes de esto no tuvieron ninguna. Los judíos, acostumbrados a la otra luz, fueron cegados ${ }^{41}$.

El judío, pues, según el inquisidor, es una persona ciega que, hasta cierto punto, sólo es declarado culpable de permanecer en la ignorancia: «éste fue más que un hombre, a saber: Dios y hombre (...). ;Ob ciegos judios! ¿Por qué no aprendéis esto ${ }^{242} \gg$. Don Martín usa constantemente este tono cansado, de hastío, como reprochando a la comunidad judía que incluso los agarenos han sido capaces de entender algo mejor que ellos las escrituras:

Es cierto que no todo el pueblo gentil fue iluminado, porque los árabes, a saber: los agarenos, permanecieron en cierta ceguera, pero no como los judíos. (...) El pueblo judío estuvo entre los ciegos, el pueblo cristiano fue el que mejor vio; el pueblo árabe, a saber: de los agarenos, fue como aquel hombre que no es totalmente ciego, sino que tiene humores en los ojos, a saber: humores del deseo. $\mathrm{Y}$ así los judíos, como ciegos, no supieron nada del mesías. Los cristianos aceptaron su luz de la mejor manera posible, aunque los agarenos aun supieron alguna $\cos ^{43}$.

Esta condescendencia hacia los judíos y esta relativa preferencia hacia musulmanes se explican por la existencia de puntos en común entre el catolicismo y el islam, como por ejemplo el culto a la virgen María o el reconocimiento de Jesús como un excelso profeta por parte de los sarracenos:

En el primer libro del Alcorán, sura segunda, acerca de la salutación a María, aleya cuadragésima quinta, aparece que el ángel dijo a María: «ioh María! Dios te anuncia una buena nueva en su palabra, cuyo nombre es el mesías, Jesús, hijo de María ${ }^{44} \gg($ Corán, 3, 45).

41 Martín GaRCíA, Sermones... [ver n. 22], f. $15 \mathrm{v}^{\circ}$ : sic fuerunt populus iudaicus et gentilis, qui iudaicus solitus erat pergere cum aliqua luce legis ueteris et adueniente Christo cessauit lux legis et sic factus fuit cecus. Sed populus gentilis solitus pergere in tenebris accepit lumen adueniente sole messie, quia ante nullum habuerat. (...) Iudei soliti alterius luminis (...) obcecati fuerunt.

42 Ibid., f. $43 \mathrm{v}^{\circ}$ : iste fuit plusquam homo, scilicet: Deus et homo (...). O ceci iudei, quare non cognoscitis hoc?

$43 \mathrm{Ibid}$., f. $15 \mathrm{v}^{\circ}$ : est uerum quod totus populus gentilis non fuit illuminatus, quia arabes, scilicet: agareni, in aliqua cecitate remanserunt, non sicut iudei. [...] Populus iudaicus fuit inter cecus; populus christianus optime uidens; populus arabicus, scilicet: agarenorum, fuit sicut ille qui non est cecus totaliter, sed habet bumores in oculis, scilicet: bumores uoluptatis. Et sic iudei, ut ceci, nibil de messia cognouerunt. Christiani optime lucem suam acceperunt, sed agareni aliqualiter cognouerunt.

44 Ibid., f. 5v : In libro primo Alchorani, azora secunda, de salutatione Marie, alea quadragesima quinta, babetur quod angelus dixit Marie: «o Maria, Deus denuntiat tibi bonum nouum in uerbo suo, cuius nomen est messias Iesus filius Marie». 
Según el parecer del Martín García, es obvio que se debe considerar a los musulmanes mucho mejor que a los judíos ${ }^{45}$ y esta es una idea que se repite a lo largo de los 156 sermones: «pues estos prójimos míos ismaelitas no se ballan en una ceguera tal como la de los judios ${ }^{46} \gg$. Es necesario tener en cuenta que uno de los argumentos de la literatura cristiana de controversia contra los judíos es el de que éstos fueron quienes crucificaron a Jesús. Este hecho, junto con la escasa (o incluso despectiva) consideración que la religión judía tiene sobre la figura de la virgen María, madre de Jesús ${ }^{47}$, provoca que los predicadores cristianos como Don Martín carguen contra los judíos y muestren cierta preferencia hacia los musulmanes:

Y así, estos herejes [judíos], o mejor, quienes erraron en la fe, deben tener muy en cuenta estas cosas y seguir el oficio de la misa y de las vísperas, sobre todo los sermones, y por la mañana deben tener devoción a la virgen María ${ }^{48}$.

\section{EL JUDÍO COMO PERSONA OBSTINADA EN SUS «ERRORES»}

El Maestre García en sus Sermones presenta a los judíos como una comunidad que realmente ha sido engañada por sus propias escrituras y sus propios rabinos. Para demostrarlo, el predicador esgrime gran cantidad argumentos exegéticos extraídos de las propias escrituras rabínicas y talmúdicas ${ }^{49}$ :

Pero vosotros, judíos, no sólo abandonasteis el significado espiritual de la ley, sino además toda la ley, aceptando que dice el Talmud, en el que hay infinitas mentiras ${ }^{50}$.

45 Acerca de la preferencia de los musulmanes frente a los judíos por parte de los cristianos vid. Ryan SZPIECH, Rhetorical Muslims: Islam as Witness in Western Christian Anti-fewish Polemic, en AlQantara, 34/1 (enero-junio 2013), pp. 153-185, passim.

46 Martín GARCÍA, Sermones... [ver n. 22], f. $344 \mathrm{r}^{\circ}$ : Isti uero proximi mei ismalite non sunt in tanta cecitate sicut iudei.

47 Isidore LOEB, La Controverse de 1240 sur le Talmud, en Revue des etudes juives, 3 (1881), pp. 39-57, p. 49. Acerca de la creencia extendida de los cristianos sobre los insultos de los judíos a María y a Jesús, vid. Cecil RoTH, The Feast of Purim and the Origins of the Blood Accusation, en Speculum, 8/4 (October 1933), pp. 520-526, passim.

48 Martín GARCÍA, Sermones... [ver n. 22], f. 462 $\mathrm{v}^{\circ}$ : Et sic isti heretici uel potius, qui in fide errauerunt, debent ista multum notare et officium misse et uesperorum continuare, maxime sermones, et de mane debent habere uirginem Mariam in deuotione.

49 Acerca de la polémica religiosa y los argumentos contra los judíos por parte de Martín García, vid. Manuel Montoza CoCA, La exégesis... [ver n. 20].

50 Martín GaRCÍA, Sermones... [ver n. 22.], f. $2 v^{\circ}$ : Sed uos, iudei, non solum dimisistis sensum spiritualem legis, sed etiam totam legem accipiendo dicta Talmuth, in quo sunt infinita mendacia. 
El mayor de los «engaños» en el que cayeron los judíos, según el inquisidor, fue el hecho de no creer que el mesías ya haya llegado con la venida al mundo de Jesús de Nazaret:

Pero los judíos fueron engañados al poner dos mesías, uno hijo de José y otro hijo de David, sin saber distinguir entre el primer y segundo advenimiento del mismo mesías $^{51}$.

Siempre según el parecer de Don Martín, a pesar de todas las «evidentes» pruebas que aportan el nuevo testamento y sus comentaristas, los padres de la Iglesia, durante siglos, los judíos siguen empeñados en no reconocer que la llegada del mesías ya se produjo. La población judía de los reinos peninsulares sigue, pues, llevando a cabo prácticas que entran en conflicto con la aceptación de este hecho (según Martín García) irrefutable e innegable, y, en consecuencia, son herejes:

Por consiguiente, el que aún hoy siga la costumbre de la circuncisión niega que todas estas cosas hayan sido cumplidas, y, por tanto, es un hereje $\mathrm{e}^{52}$.

Dependiendo de la ocasión o, seguramente, del público ante el que esté predicando, el obispo de Barcelona recurre a tópicos y estereotipos sobre los que atacar a los judíos con el fin de exaltar a la audiencia o coaccionar a aquellos que tengan una actitud más tibia o pasiva frente a los judíos o las prácticas judaizantes:

Desde la cuna son alimentados con el odio a Cristo y a los cristianos y a la ley de Cristo, y en sus sinagogas nos maldicen cada día ${ }^{53}$.

Esta actitud perseverante tiene como resultado la expulsión de 1492, que Martín García celebra como un hecho triunfal y memorable, muy a tener en consideración a favor de sus artífices, los reyes Católicos:

La novena saeta la envió contra los judíos de toda España, pues como vieron sus majestades los reyes que éstos depravaban la fe de Cristo y propiciaban el fomento de la ley mosaica, los expulsaron de toda España ${ }^{54}$.

51 Martín García, Sermones... [ver n. 22], f. 5v : Sed iudei fuerunt decepti ponentes duos messias, unum filium Ioseph, alterum filium Dauid, nescientes distinguere inter primum et secundum aduentum eiusdem messie.

52 Ibid., f. 443r ${ }^{\circ}$ : Igitur, qui nunc seruaret circumcisionem negaret omnia ista esse impleta et sic esset hereticus.

$53 \mathrm{Ibid}$., f. $6 \mathrm{v}^{\circ}$ : a cunabulis sunt nutriti in odium Christi et christianorum et legis Christi, et in synagogis suis maledicunt cotidie nos.

54 Ibid., f. 476r ${ }^{\circ}$ : Nonam sagittam misit contra iudeos totius Hispanie, nam cum uiderent domini reges quod isti deprauabant fidem Christi et fomentum prestabant legi mosaice, a tota Hispania illos expulerunt. 
En el vigésimo segundo sermón de la compilación, pronunciado con ocasión de la promulgación del edicto de expulsión ${ }^{55}$, Don Martín también recoge el caso del santo niño de La Guardia, en el que, supuestamente, hacia 1490 un niño fue asesinado de forma ritual por judíos y $\operatorname{conversos}^{56}$ :

Pues tan enconados estáis en destruir la fe de Cristo que incluso en estos días matasteis a un niño en el reino de Castilla ${ }^{57}$.

Este mismo sermón vigésimo segundo está fechado, según Cirac Estopañán ${ }^{58}$, el 29 de abril de 1492, es decir, justo un mes después de la publicación del edicto de expulsión. Dada la coyuntura de los acontecimientos, el dominico aprovecha para hacer hincapié en los malos usos de la población judía y presenta a la Inquisición como una institución de bien a la que no deben de temer:

No hagáis ayuno, ni oraciones ni festividades ni el «sabbat», ni la circuncisión. No debéis prestar atención a los alimentos ni a los vocablos en hebreo ni a los textos judíos (....). Y así, no temáis a la Inquisición, porque ya no habrá judíos ni persuasión de los malvados ${ }^{59}$.

En este clima de tensión y con la presión de actuar rápidamente, Don Martín apremia a los judíos que todavía viven en su congregación y les insta a convertirse en el plazo mandado por los reyes Católicos. El predicador se sirve de la historia del apóstol Tomás, que hasta que no tocó a Jesús no creyó en él, y compara al pueblo judío con el discípulo, incitándoles a bautizarse antes de que sea tarde para ellos:

He aquí que si crees en Cristo, has de saber que tendrás la vida eterna y el descanso en esta tierra. En caso contrario, que sepas que hay un decreto, el cual

55 Martín García, Sermones... [ver n. 22], f. 52 $\mathrm{r}^{\circ}$ : Sermo uicesimus secundus contra bereticos et infideles octo die resurrectionis in publicatione edicti iudeorum in quo probatur messiam esse Deum et hominem.

56 La historia del infante asesinado por judíos con el objetivo de llevar a cabo prácticas rituales tiene su origen en las difamaciones contra los judíos y es un tema absolutamente legendario que aparece desde mediados del siglo XIII y es, asimismo, recogido por Alfonso de Espina. Vid. Evelyne KENIG, Historia de los judíos españoles hasta 1492, Barclona, 1995, p. 150. Vid. etiam: Henry Charles LEA, El Santo Niño de la Guardia, en The English Historical Review, 4/14 (April 1889), pp. 229-250, p. 236.

57 Martín GARCía, Sermones... [ver n. 22], f. 53v $:$ Nam conati estis fidem Christi destruere, etiam his diebus in regno Castelle puerum interfecistis.

58 Sebastián CiRAC EsTOPAÑáN, Los sermones... [ver en n. 22], p. 67.

59 Martín GARCÍA, Sermones... [ver n. 22], f. 53r ${ }^{\circ}$ : Non faciatis ieiunia, non orationes, non festiuitates nec sabbatum, non circumcisione. De escibus comestibilibus non est curandum, non de uerbis hebraicis, non de lectura iudaica (...). Et sic ne timeatis inquisitionem, quia iam non erunt iudei nec malorum persuasiones. 
te anuncio, sobre el mandato de sus majestades los reyes y del señor inquisidor: que el que no fuere bautizado marche de su dominio antes de tres meses a contar desde este día ${ }^{60}$.

A estos factores culturales, religiosos y sobre todo políticos, se les suman las prácticas que algunos judíos mantienen como costumbre y que son vistas como heréticas por parte de las autoridades, en este caso, de la inquisición:

Existe una herejía de los neófitos, que tenemos ante nosotros. Éstos tienen como precepto abstenerse de las carnes que no son preparadas por judíos. También de las carnes de origen porcino. También de la grasa. También se abstienen del nervio de Jacob, que vulgarmente se llama «glandólica» ${ }^{61}$.

Por último, resulta igualmente interesante señalar algunas de las escasas menciones en la obra de Martín García a judíos ya convertidos. Por desgracia, no disponemos en los sermones de datos suficientes para poder afirmar si estos conversos acuden al bautismo por voluntad propia o si, por el contrario, son coaccionados o forzados a estos actos:

La higuera (de la redención) ya comienza a dar fruto mediante la conversión de algunos judíos, y también otros árboles de los gentiles ismaelitas comienzan a dar su fruto en Hispania mediante su conversión. Por tanto, es necesario creer que se aproxima la redención ${ }^{62}$.

En el anterior pasaje se deja entrever, ciertamente, el tono esperanzado del obispo de Barcelona respecto a la política unificadora de la Inquisición bajo una sola fe. Este cometido siempre se encuadra (en mayor o menor medida) en la misión política unionista de los Reyes Católicos ${ }^{63}$, cuyas consecuencias en ocasio-

60 Martín GARCÍA, Sermones... [ver n. 22], f. 53r ${ }^{\circ}$ : Ecce si in Christum credis, scias te habere uitam eternam et requiem in hac terra. Alias scias esse decretum, quod tibi nuntio, de mandato dominorum regum et domini inquisitoris, quod qui non fuerit baptizatus exeat dominium suum infra tres menses ab ista die computandos.

$61 \mathrm{Ibid}$., f. 396 v ${ }^{0}$ : Est heresis neophitorum, quam in manibus habemus. Qui precipiunt abstinere a carnibus que non sunt per iudeos preparate. Item a carnibus porcinis. Item a pinguedine. Item a neruo Iacob, quod unlgariter dicitur «glandolica». Acerca de la glandólica, vid. Enrique CANTERA MONTENEGRO, La carne y el pescado en el sistema alimentario judío en la España medieval, en Espacio, Tiempo y Forma, Serie III, Historia Medieval 16 (2003), pp. 13-51, p. 22.

62 Martín GARCÍA, Sermones... [ver n. 22], f. 87 ro: ficus incepit iam fructificare per conuersionem aliquorum iudeorum, et alie arbores gentilium ismahelitarum per conuersionem in Hispania incipiunt facere fructum. Igitur credendum est quod redemptio appropinquat.

63 Ángel AlCalá Galve, Política religiosa de los Reyes Católicos. La Inquisición. La expulsión de los judíos, en Julio VALdeón BaRUQue (ed.), Isabel la Católica y la política, Madrid, 2001, pp. 117-156, 
nes provocan cierto malestar social entre los conversos, como reconoce Martín García, que les insta a adoptar una actitud paciente y sobre todo, conformista, apoyándose en pasajes bíblicos:

Si dices: nosotros los judíos conversos somos como cautivos y despreciados, porque todos nos llaman «neófitos». Yo te digo que tú debes fijarte en aquello que decía David en el Salmo octogésimo tercero: «preferí ser despreciado en la casa de mi Dios antes que vivir entre las tiendas de los pecadores» (Psal. 83, 11) ${ }^{64}$.

\section{REFLEXIONES FINALES}

La literatura de controversia religiosa y de polémica contra los judíos tiene una larga y constante tradición en la península ibérica, cuyo inicio podríamos situar en el Concilio de Elvira del año $337^{65}$. Esta tradición de obras polémicas, como es obvio, sufre altibajos y algunos momentos de mayor o menor producción, pero, no obstante, la sucesión de diferentes acontecimientos durante las últimas décadas del siglo XV y la política unificadora de los Reyes Católicos, tanto política como religiosa, propician que se intensifiquen los ataques contra los judíos y se les juzgue como presuntos causantes de los males que azotan en ese momento a la Corona. También en los Sermones de Don Martín García se aprecia una clara animadversión hacia los judíos. No obstante, es bastante significativo que al margen del antijudaísmo tradicional de las obras de polémica, como el Fortalitium Fidei de Alfonso de Espina o del Pugio Fidei de Ramón Martí6 ${ }^{66}$ el Maestre tienda a utilizar un tono de leve reproche o incluso condescendiente. Esto se debe, muy probablemente, a que la situación respecto a los judíos, musulmanes y

pp. 135-136: «No se hable de un pretendido intento de los Reyes Católicos de establecer la unidad religiosa como si ésta fuera indispensable para la unidad política; sí, de su empeño por lograr la unidad nacional. [...] Bien valía la pena utilizar al servicio de sus fines políticos -de pacificación popular primero, y de unidad nacional después- una institución (su Inquisición, una Inquisición "a su gusto")».

64 Martín GARCÍA, Sermones... [ver n. 22], f. 8v: Si dicis: nos iudei conuersi sumus sicut captiui et deiecti, quia omnes uocant nos «neophitos». Dico quod tu debes notare illud quod dicebat Dauid Psalmi octogesimo tertio: elegi abiectus esse in domo Dei mei, magis quam habitare in tabernaculis peccatorum.

65 Carlos Del VAlle Rodríguez (ed.), La controversia judeocristiana en España (desde los orígenes basta el siglo XIII). Homenaje a Domingo Muñoz León, Madrid, 1998, pp. 15-19.

66 José María MONSALVO ANTÓN, Ideología y anfibología antijudías en la obra Fortalitium Fidei, de Alonso de Espina. Un apunte metodológico, en Pablo DE LA CRUZ DÍAZ, Fernando Luis CORRAL y Iñaki MARTín VISO (eds.), El historiador y la sociedad. Homenaje al profesor Fosé María Mínguez, Salamanca, 2013, pp. 163-189, p. 163. 
herejes en general, cambia de forma sustancial desde el tercer cuarto del siglo XV y culmina con el decreto de expulsión de 1492.

El tono indulgente de Don Martín García se adecúa a la voluntad de coaccionar hacia la conversión más que hacia la expulsión efectiva o a la aniquilación. Este hecho se corresponde al problema de cómo asimilar a la población conversa, cómo han de ser «educados» y cómo se les ha de considerar. Este tema, que Eloy Benito Ruano denominó «el problema converso ${ }^{67} \gg$ es una cuestión compleja en la que intervienen factores políticos y sociales en los que no profundizaremos en este momento.

Por otra parte, desde finales del siglo XV la Inquisición amplía paulatinamente sus competencias, erigiéndose en guardiana de la fe Católica y encargándose de regular todos los aspectos relacionados con la doctrina. Sus acciones no solo se dirigen hacia judíos en particular, sino que se extienden a todos los aspectos de la vida cotidiana susceptibles de herejía ${ }^{68}$, como apuntábamos antes.

En su sermón, el inquisidor apostólico predica que, en realidad, la redención de los pecados cometidos y la expiación de la culpa por persistir en la herejía están al alcance de todos, siempre que se lleve a cabo una sincera conversión a la fe católica. Por ello, insta a los pecadores, vengan de donde vengan y profesen la fe que profesen, a que abracen la verdadera fe:

$\mathrm{Y}$ tal y como estos reyes acudieron al unísono e igual premio obtuvieron, así nosotros debemos acudir al unísono a Cristo sin ninguna distinción. No se debe considerar si se procede del judaísmo o si se procede de entre los agarenos o los gentiles o los griegos, etcétera, sino que se debe considerar que acudiendo a Cristo son cristianos, porque en Cristo «no hay judío ni griego» (Gal. 3, 8), a los Gálatas tercero. $\mathrm{Y}$ así, no debemos hacer ninguna distinción en los conversos, porque en Cristo «no hay distinción entre judíos y griegos» (Rom. 10, 12), a los Romanos décimo. Y así, todos han de ser llamados y considerados cristianos ${ }^{69}$.

Realmente, el que es probablemente el eclesiástico más poderoso de Aragón en ese momento y, como apuntábamos, seguramente el más temido ${ }^{70}$, no tiene

67 James S. AMELANG, Historias... [ver n. 27], p. 110.

68 Ángel AlCalá GaLVE, Literatura y Ciencia ante la Inquisición Española, Madrid, 2001, pp. 12-13.

69 Martín GARCÍA, Sermones... [ver n. 22], f. 449r ${ }^{\circ}$ : Et sicut isti reges uniformiter uenerunt et eadem munera illi obtulerunt, sic nos uniformiter non cum aliqua distinctione in Christo. Non considerare si uenit ex iudaismo nec si uenit ex agarenis uel gentibus et grecis, etcetera, sed considerare quod uenientes ad Christum sunt christiani, quia in Christo: non est iudeus neque grecus, ad Galatas tertio. Et sic in conuersis nullam debemus facere distinctionem, quia in Christo: nec est distinctio iudei et greci, ad Romanos decimo. Et sic omnes sunt dicendi et reputandi christiani.

70 Vid. Juan Francisco SánChez Martín, Martín García Puyazuelo y su papel en el establecimiento de la Inquisición en Aragón, en Anuario del Centro de la Universidad Nacional de Educación a Distancia en Calatayud, 1/13 (2005), pp. 233-243, p. 234: «uno de los aragoneses más poderosos de su tiempo». 
una necesidad real de adoptar esta actitud conciliadora en su discurso. Sin embargo, parece que los intereses que motivan al inquisidor dominico son de carácter puramente teológico, que se añaden a la tradición de los argumentos esgrimidos a favor de los conversos por autores como Alonso de Oropesa o Alonso de Cartagena $^{71}$. Con esto no queremos decir que Don Martín busque desinteresadamente la conversión de estos grupos de población, pero sí que se deja entrever cierto fervor religioso en algunos pasajes de sus sermones, como cuando afirma que «los blasfemos son peores que los judíos ${ }^{72} \gg$.

71 Vid. Cándida Ferrero HernáNDeZ, Literatura latina de controversia religiosa en la Castilla del siglo XV: una aproximación a su tipología, en José MARTíNEZ GÁZQUEZ, Óscar DE LA CRUZ PALMA y Cándida FERrero Hernández (eds.), Actas del V Congreso Internacional de Latín Medieval Hispánico, Barcelona, 7-10 de septiembre de 2009, Firenze, 2011, pp. 425-441, pp. 439-440.

72 Martín GaRCÍA, Sermones... [ver n. 22], f. $113 v^{\circ}$ : blasphemi sunt peiores iudeis. 